\title{
FINITE ELEMENT BASED STATIC AND DYNAMIC ANALYSIS OF TENSAIRITY SPINDLE STRUCTURE
}

\author{
Beyons Thomas ${ }^{1}$, Anumod A.S. ${ }^{2}$ \\ ${ }^{I}$ M.Tech student, Department of Civil Engineering, ICET, Kerala, India \\ ${ }^{2}$ Asst.Professor,Department of Civil Engineering, ICET, Kerala, India
}

\begin{abstract}
Tensairity is the new structural concept.It contains the combination of cable,membrane,struts and low pressure compressed air.The role of the membrane and air is to stabilize the compression element against buckling and the cable.The technology is good suited for wide span roofs,temporary bridges, domes etc. In this paper finite element based static and dynamic analysis of spindle shaped Tensairity beam is studied.In this paper also includes the parametric studies and determine the natural frequencies and deflections of the beam under different loading.Also determines load-displacement response of the spindle shaped Tensairity beam.
\end{abstract}

Key Words: Tensairity

\section{INTRODUCTION}

Tensairity is the new light weight structural concept.It contains the combination of membrane, chords and low pressurized compressed air. The key principle of Tensairity structure is to use low pressure air to stabilize compression elements against buckling. It has same load bearing capacity of conventional steel girders. The compressive load is taken by the upper chord and tension load is taken by lower chord.And the pressurized hull prevent the structure from buckling while loading.

\subsection{Structure and behavior of Tensairity beam}

Tensairity beam consists of compression and tension element and they are separated by the inflated hull.The basic shape of Tensairity beam is cylinder.It use low pressure air to stabilize compression element against buckling.In cylindrical beam in which the tension and compression elements are fixed together at the ends and.

The pressurized hull is used to stabilize the compression element against bucklingThe tension element are of two in number and which are spiraled around the hull.These tension cables connected to the straight compression element at the ends.

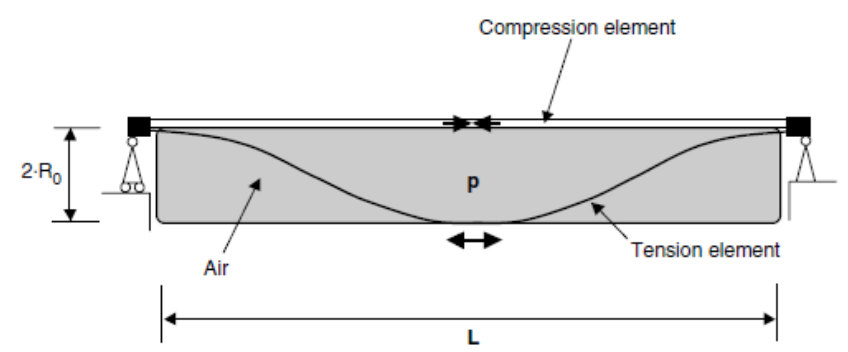

Fig -1: Cylindrical shaped Tensairity beam

\subsection{Spindle shaped Tensairity beam}

The first Tensairity beam is based on cylindrical shape form.From further investigations understand that spindle shape Tensairity beam are more stiffer than cylindrical shape Tensairity beam with same length,diameter and internal pressure.In spindle shape beam the helical shape tension cables are avoided.The tension and compression elements are curved shape and fixed together at the ends.They are separated by pressurized hull for stabilizing the compressioin member against buckling.

The roof of the parking garage in Montreux are based on spindle shaped Tensairity girders. The representation of spindle Shaped Tensairity beam is given below.

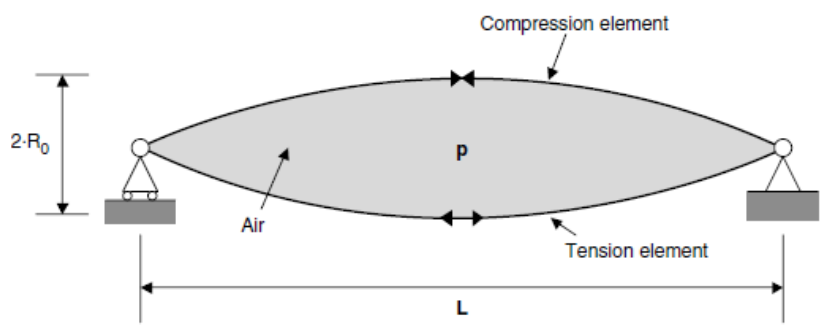

Fig -2: spindle shaped Tensairity beam

\subsection{Adavantages and Applications}

The main advantages of Tensairity structure includes light weight, fast seup,low storage volume and large load bearing capacity.This can be used for mainly temporary structures. The main advantage is aesthetic appearance. Any architectural shape can be constructed by using this technique. 
The main application includes the roof structures of parking, stadium, temporary bridges,foot bridges ,domes etc.

\section{FINITE ELEMENT ANALYSIS}

Finite element based static and dynamic analysis of spindle shaped Tensairity beam is done. For the modelling and analysis finite element software ANSYS is used.

\subsection{Model for the analysis}

FE-model uses BEAM189 elements for chord and SHELL281 elements for fabric.The air pressure is modeled as a surface load on the SHELL .Fabric is considered as a linear isotropic material having modulus of elasticity $E=2.14 \times 10^{8} \mathrm{~N} / \mathrm{m}^{2}$.The spindle shaped Tensairity beam having length is $5 \mathrm{~m}$. and central diameter is $0.5 \mathrm{~m}$. The thickness of polyamide fabric is $5 \mathrm{~mm}$. and the density is $620 \mathrm{~kg} / \mathrm{m}^{3}$ The tension and compression element is made up of aluminium having in rectangular shape with width $3 \mathrm{~mm}$ and depth is $1 \mathrm{~mm}$.At support is dimension changes to $0.35 \times 0.15 \mathrm{~mm}$. The modulus of elasticity of aluminium chord is $E=69 \times 10^{9}$ $\mathrm{N} / \mathrm{m}^{2}$ and density is $2700 \mathrm{~kg} / \mathrm{m}^{3}$. Pressure applied internally by $150 \mathrm{mbar}$.

The dimensions of spindle shaped Tensairity beam is represented below

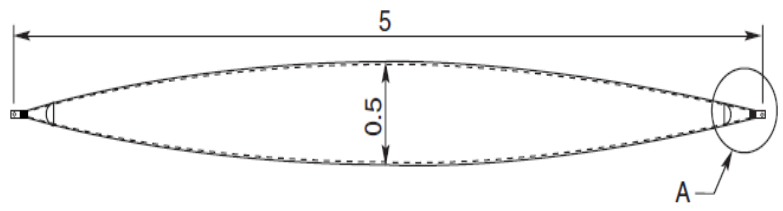

Fig -3: Longitudinal section dimension



Fig -4: Cross section dimension

Tensairity beam is simply supported at the end. The modeled spindle shaped Tensairity beam is shown in below.

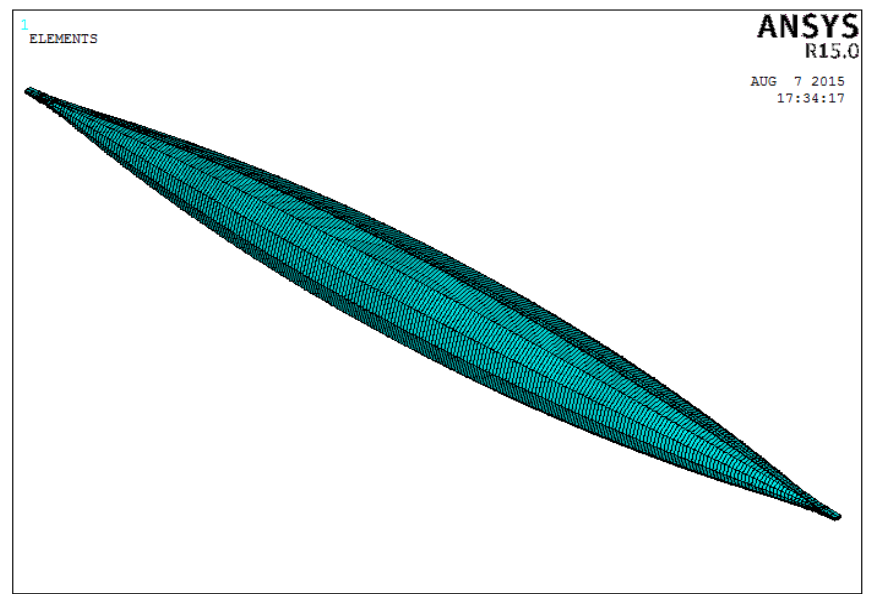

Fig -4: Meshed model of Tensairity beam

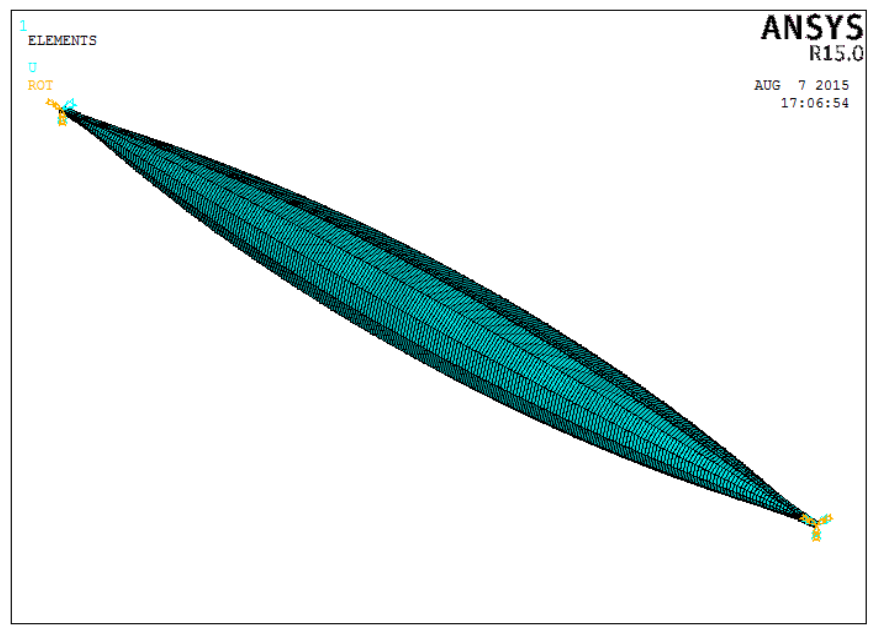

Fig -5: Simply supported Tensairity beam

\section{RESULTS}

We have studied the behavior of the spindle for bending under a central load.And the behavior of the spindle shaped Tensairity beam under different pressures.

\subsection{Modal analysis with different internal pressures}

Modal analysis of Tensairity beam with two different pressures $100 \mathrm{mbar}$ and $200 \mathrm{mbar}$ are done.The first four natural frequencies of the $100 \mathrm{mbar}$ pressure are $6.352 \mathrm{~Hz}$, $7.2509 \mathrm{~Hz}, 17.561 \mathrm{~Hz}$ and $24.252 \mathrm{~Hz}$.The mode shape of the above different frequencies are given in below. 


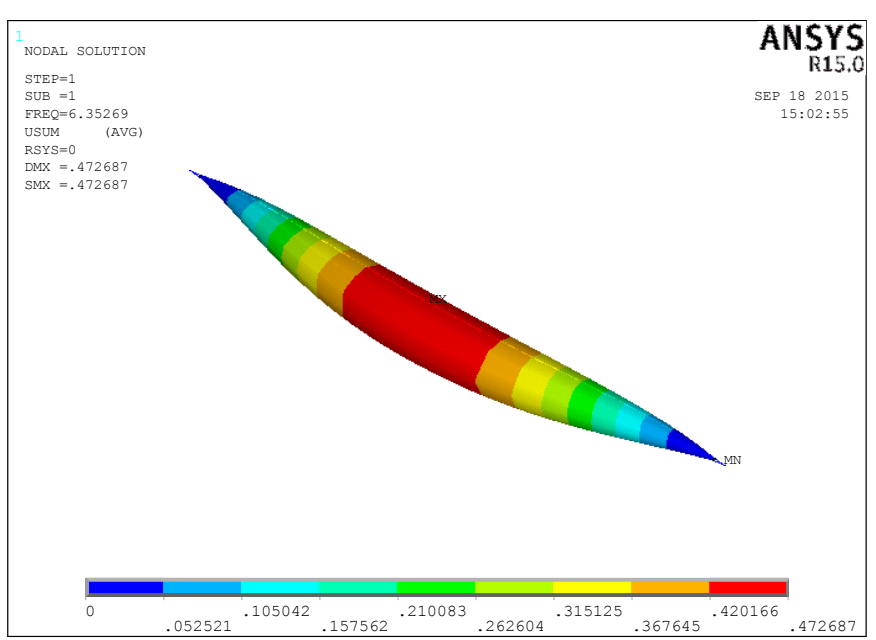

Fig -6: Mode shape for $6.352 \mathrm{~Hz}$

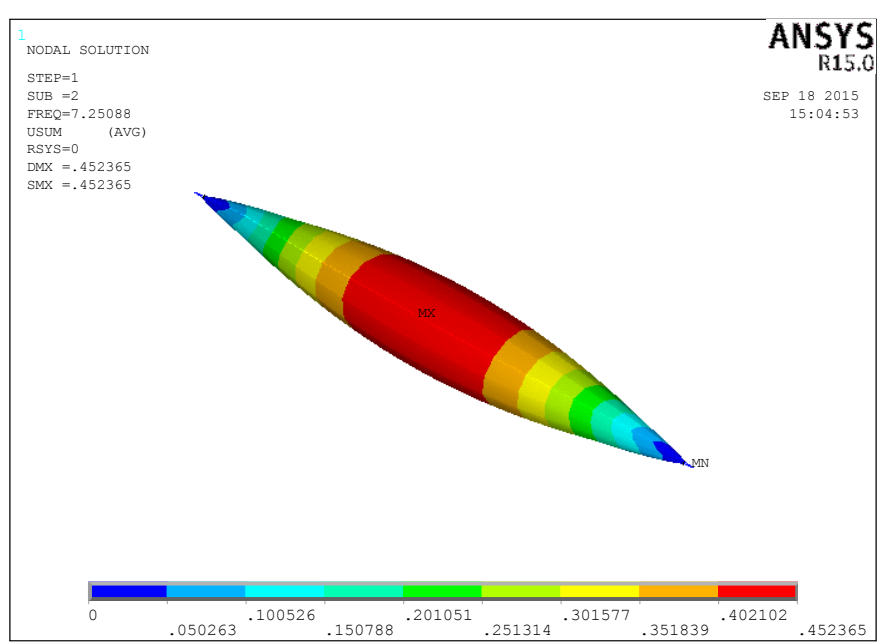

Fig -7: Mode shape for $7.25 \mathrm{~Hz}$

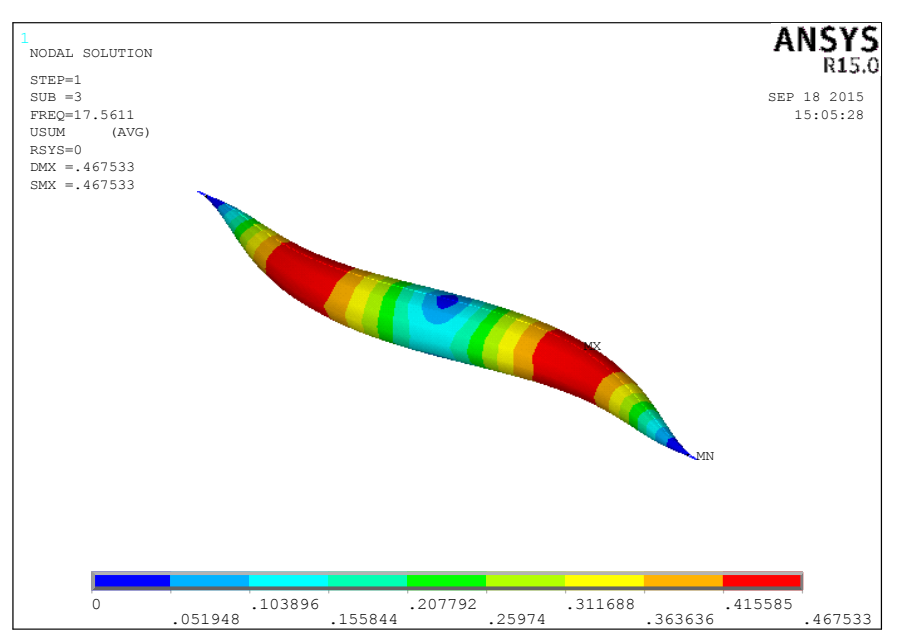

Fig -8: Mode shape for $17.56 \mathrm{~Hz}$

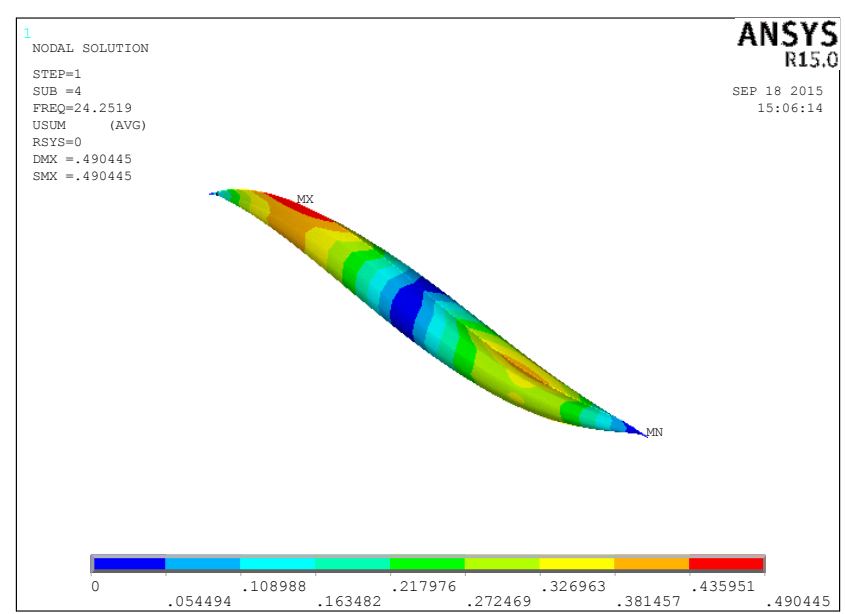

Fig -9: Mode shape for $24.252 \mathrm{~Hz}$

The first four natural frequencies of the 200mbar pressure are $6.405 \mathrm{~Hz}, 7.314 \mathrm{~Hz}, 17.666 \mathrm{~Hz}$ and $24.937 \mathrm{~Hz}$. The mode shape of the above different frequencies are given in below

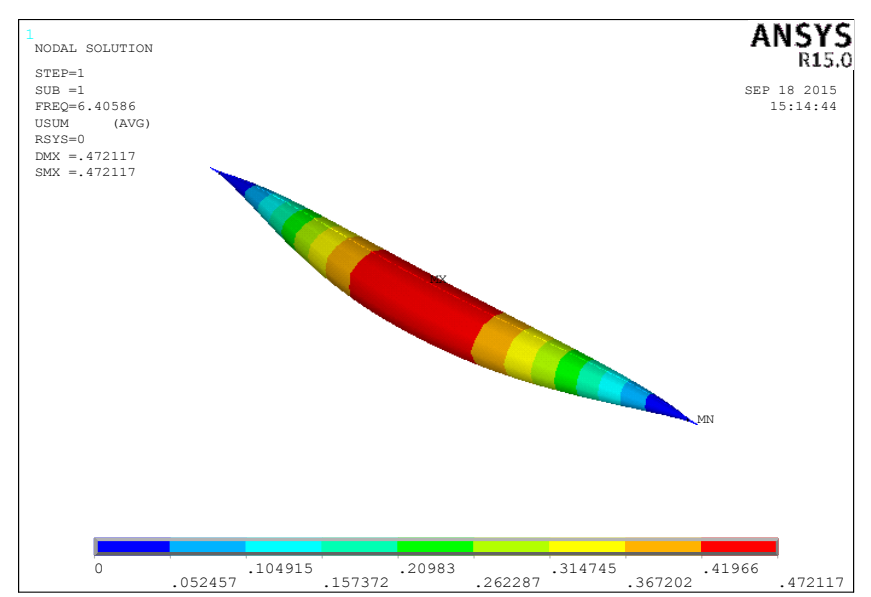

Fig -10: Mode shape for $6.405 \mathrm{~Hz}$

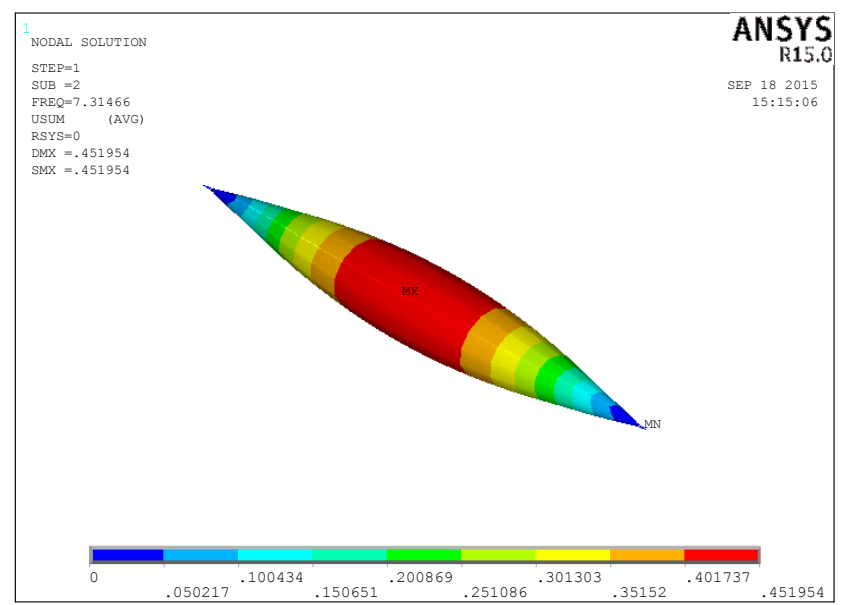

Fig -11: Mode shape for $7.314 \mathrm{~Hz}$ 


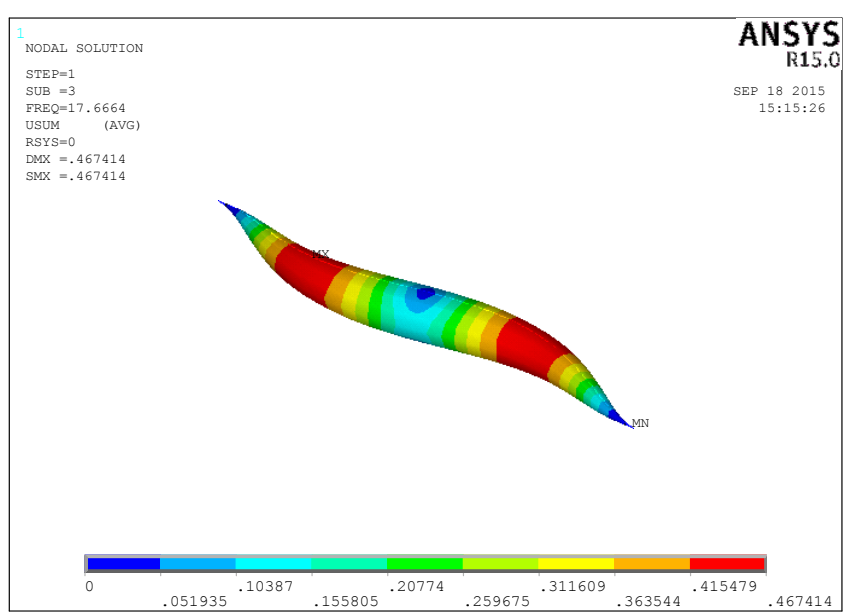

Fig -12: Mode shape for $17.66 \mathrm{~Hz}$



Fig -13: Mode shape for $24.937 \mathrm{~Hz}$

Table -1: Comparison of frequencies

\begin{tabular}{|c|c|}
\hline $\begin{array}{c}\text { Frequency for 100mbar } \\
\text { pressure }\end{array}$ & $\begin{array}{c}\text { Frequency for 200mbar } \\
\text { pressure }\end{array}$ \\
\hline $6.3527 \mathrm{~Hz}$ & $6.4059 \mathrm{~Hz}$ \\
\hline $7.2509 \mathrm{~Hz}$ & $7.3147 \mathrm{~Hz}$ \\
\hline $17.561 \mathrm{~Hz}$ & $17.666 \mathrm{~Hz}$ \\
\hline $24.252 \mathrm{~Hz}$ & $24.937 \mathrm{~Hz}$ \\
\hline
\end{tabular}

The variation between frequencies under two different pressures are very small.So there is not much effect on design of Tensairity beam.

\subsection{Modal Analysis With Different Material Of}

\section{Tension And Compression Chord}

Modal analysis of Tensairity beam with three different compression and tension members are done.The three different materials are aluminium,steel and copper.For the anlysis polyamide fabric Tensairity beam with $150 \mathrm{mbar}$ internal pressure are used.The first four natural frequencies for these members are given below.
Table -2: Comparison of frequencies

\begin{tabular}{|c|c|c|}
\hline Aluminium & Steel & Copper \\
\hline $6.38 \mathrm{~Hz}$ & $6.23 \mathrm{~Hz}$ & $4.66 \mathrm{~Hz}$ \\
\hline $7.30 \mathrm{~Hz}$ & $6.91 \mathrm{~Hz}$ & $5.27 \mathrm{~Hz}$ \\
\hline $17.61 \mathrm{~Hz}$ & $15.83 \mathrm{~Hz}$ & $12.79 \mathrm{~Hz}$ \\
\hline $24.67 \mathrm{~Hz}$ & $17.22 \mathrm{~Hz}$ & $14.51 \mathrm{~Hz}$ \\
\hline
\end{tabular}

From above these values, the tension and compression element of aluminium having greater natural frequencies than other two material. While desigining this should be taken into account.

\subsection{Modal Analysis With Different Fabric Material}

Modal analysis of Tensairity beam with four different fabric materials are done.The four different fabric materials used are polyamide, PVC coated polyester, silicon and rubber.For the anlysis Tensairity beam contains tension and compression element aluminium rod and 150mbar internal pressure.The first four natural frequencies for these members are given below.

Table -3: Comparison of frequencies

\begin{tabular}{|c|c|c|c|}
\hline Polyamide & $\begin{array}{c}\text { PVC coated } \\
\text { polyester }\end{array}$ & Silicon & Rubber \\
\hline $6.38 \mathrm{~Hz}$ & $9.44 \mathrm{~Hz}$ & $15.61 \mathrm{~Hz}$ & $5.40 \mathrm{~Hz}$ \\
\hline $7.30 \mathrm{~Hz}$ & $11.83 \mathrm{~Hz}$ & $46.73 \mathrm{~Hz}$ & $5.99 \mathrm{~Hz}$ \\
\hline $17.61 \mathrm{~Hz}$ & $32.44 \mathrm{~Hz}$ & $53.19 \mathrm{~Hz}$ & $15.09 \mathrm{~Hz}$ \\
& & & \\
\hline $24.67 \mathrm{~Hz}$ & $38.96 \mathrm{~Hz}$ & $72.38 \mathrm{~Hz}$ & $16.03 \mathrm{~Hz}$ \\
& & & \\
\hline
\end{tabular}

From above results, Tensairity beam with silicon fabric shows higher natural frequencies than other three.And the rubber fabric having very low natural frequiencies. While desigining this should be taken into account.

\subsection{Modal Analysis With Different Area Of Cross}

\section{Section Of Tension And Compression Rod}

Modal analysis of Tensairity beam with three different cross section of tension and compression rod are done.The three different cross sections are $30 X 10,20 X 20,25 X 15 \mathrm{~mm}$.For the anlysis Tensairity beam contains tension and compression element aluminium rod and 150mbar internal pressure.The first four natural frequencies for these members are given belown. 
Table -3: Comparison of frequencies

\begin{tabular}{|c|c|c|}
\hline $\mathbf{3 0 X 1 0}$ & $\mathbf{2 0 X 2 0}$ & $\mathbf{2 5 X 1 5}$ \\
\hline $6.38 \mathrm{~Hz}$ & $4.87 \mathrm{~Hz}$ & $5.59 \mathrm{~Hz}$ \\
\hline $7.30 \mathrm{~Hz}$ & $5.62 \mathrm{~Hz}$ & $6.42 \mathrm{~Hz}$ \\
\hline $17.61 \mathrm{~Hz}$ & $13.36 \mathrm{~Hz}$ & $15.39 \mathrm{~Hz}$ \\
\hline $24.67 \mathrm{~Hz}$ & $22.97 \mathrm{~Hz}$ & $23.01 \mathrm{~Hz}$ \\
\hline
\end{tabular}

From above results, Tensairity beam with 30X10mm cross section of rod shows higher natural frequencies than other two.And the $20 \times 20 \mathrm{~mm}$ cross section having very low natural frequiencies. While desigining this should be taken into account.

\subsection{Study Of Load-Displacement Response Of The}

\section{Spindle Shape Tensairity Beam}

For the study of load displacement response of Tensairity beam, introduced a central load at The center of the compression chord of the beam.By changing the load corresponding deflection of beam is noted for the pressure of $150 \mathrm{mbar}$ and load displacement response is represented by graph given below.

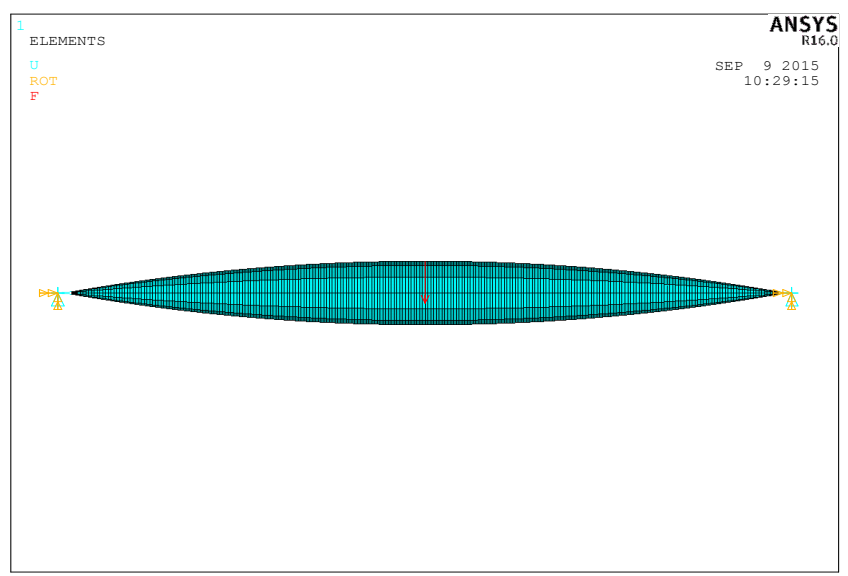

Fig -14: Tensairity beam with central load

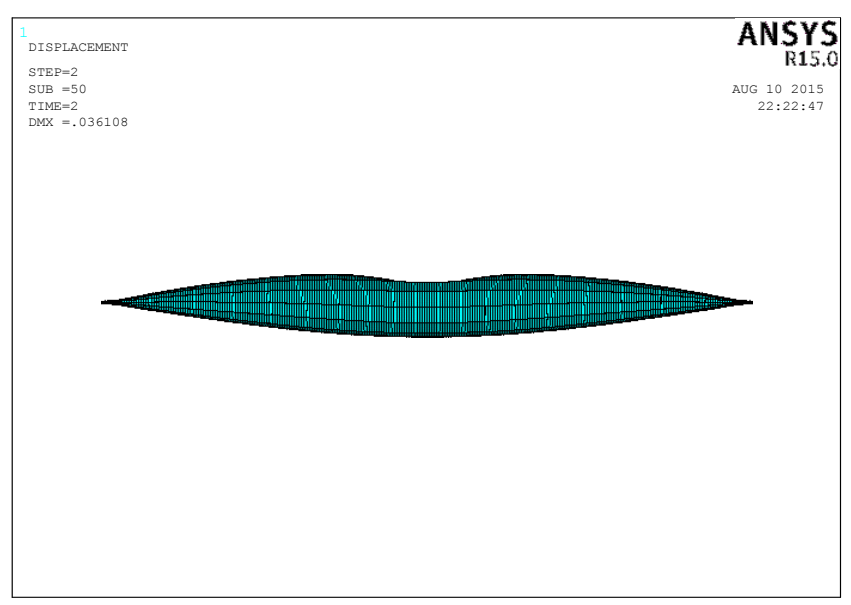

Fig -15: Deformation of Tensairity beam

\subsection{Load-Displacement Response For Different} Tension And Compression Materials

Material properties of different material are given below .

Table -4: Material properties

\begin{tabular}{|c|c|c|c|}
\hline Material & $\begin{array}{c}\text { Modulus of } \\
\text { elasticity }\left(N / \mathrm{m}^{2}\right)\end{array}$ & $\begin{array}{l}\text { Density } \\
\left(\mathrm{kg} / \mathrm{m}^{3}\right)\end{array}$ & $\begin{array}{c}\text { Poisson's } \\
\text { ratio }\end{array}$ \\
\hline Steel & $210 \times 10^{9}$ & 7800 & 0.3 \\
\hline Copper & $120 \times 10^{9}$ & 8940 & 0.35 \\
\hline Aluminium & $69 \times 10^{9}$ & 2700 & 0.33 \\
\hline PVC & $4.1 \times 10^{9}$ & 1390 & 0.4 \\
\hline Silicon & $185 \times 10^{9}$ & 2330 & 0.27 \\
\hline Rubber & $0.1 \times 10^{9}$ & 1100 & 0.46 \\
\hline Polyamide & $2.14 \times 10^{8}$ & 620 & 0.34 \\
\hline
\end{tabular}

The analysis of spindle shape Tensairity beam with three different compression and tension members are done.The three different materials are aluminium,steel and copper.For the anlysis polyamide fabric Tensairity beam with $150 \mathrm{mbar}$ internal pressure are used.The load displacement response is shown in the below graph

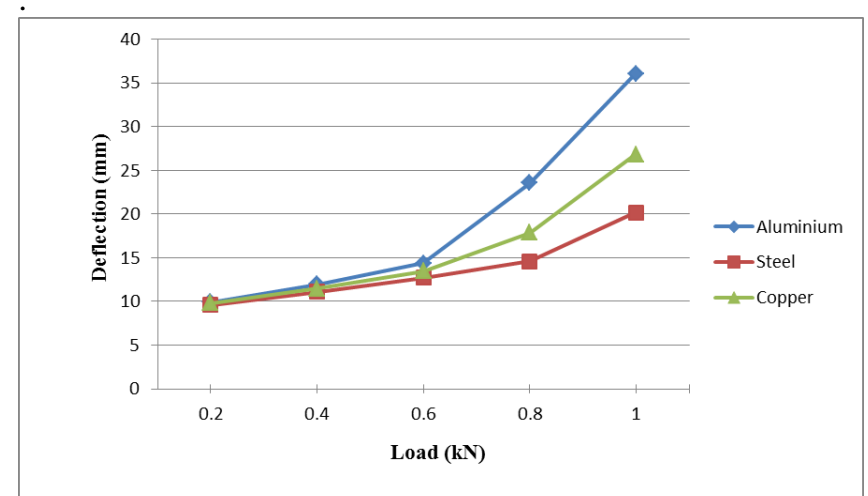

Graph -1: Load-displacement response graph

From above the graph,spindle shape Tensairity beam with aluminium rod shows greater displacement than other two material.Tensairity beam with steel rod shows minimum displacement.so spindle shape Tensairity beam with Steel rod will produce greater stiffness than aluminium and copper.

\subsection{Load-Displacement Response For Different Fabric Materials}

The analysis of spindle shape Tensairity beam with four different fabric materials are done.The four different materials are plyamide, PVC coated polyester, silicon and 
rubber. For the anlysis Tensairity beam with $150 \mathrm{mbar}$ internal pressure and aluminium rod are used.The load displacement response is shown in the below graph.

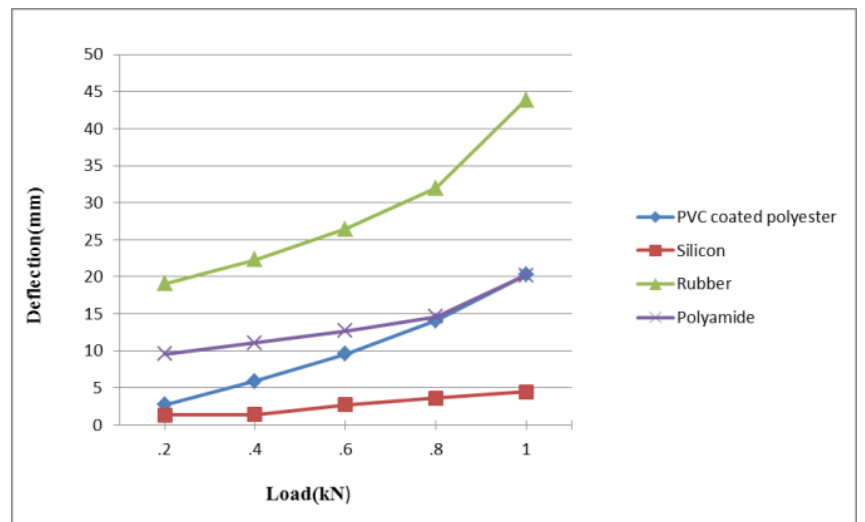

Graph -2: Load-displacement response graph

From above the graph, spindle shape Tensairity beam with rubber fabric shows greater displacement than other three material.Tensairity beam with silicon shows minimum displacement.so spindle shape Tensairity beam with silicon fabric will produce greater stiffness than other three fabric.

\subsection{Load-Displacement Response For Different}

\section{Internal Pressures}

The analysis of spindle shape Tensairity beam with three different fabric materials are done.The three different pressures $100 \mathrm{mbar}$, 150mbar and 200mbar .For the anlysis Tensairity beam having aluminium rod with polyamide fabric are used.The load displacement response is shown in the below graph

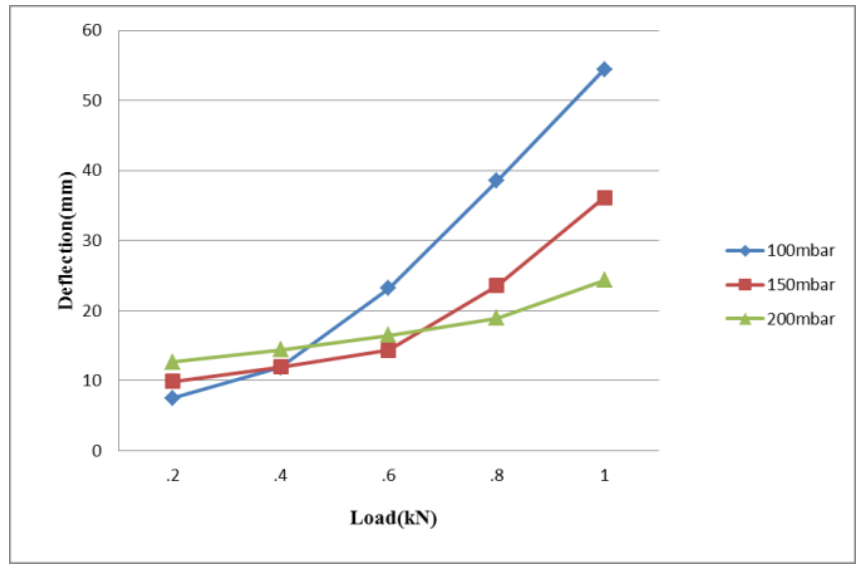

Graph -3: Load-displacement response graph

From above the graph, spindle shape Tensairity beam with 100mbar shows greater displacement than other two pressures.Tensairity beam with $200 \mathrm{mbar}$ shows minimum displacement.so spindle shape Tensairity beam with lower internal pressure will produce greater stiffness.

\subsection{Load-Displacement Response For Different}

\section{Area Of Cross Sections}

The analysis of Tensairity beam with three different cross section of tension and compression rod are done.The three different cross sections are 30X10 ,20X20,25X15mm. For the anlysis Tensairity beam contains tension and compression element aluminium rod and 150mbar internal pressure. The load displacement response is shown in the below graph.



Graph -4: Load-displacement response graph

From above the graph ,spindle shape Tensairity beam with $30 \times 10 \mathrm{~mm}$ shows greater displacement than other two dimensions. Tensairity beam with $20 \times 20 \mathrm{~mm}$ shows minimum displacement.so while designing spindle shape Tensairity beam the cross section of tension and compression elements should be consider into account..

\section{CONCLUSIONS}

The important conclusions drawn from the various parametric studies are sumarised.

- From modal analysis seen that variation between frequencies under two different pressures are very small. So there is no effect on design of Tensairity beam.

- The tension and compression element having low modulus of elasticity produce greater natural frequencies.. While desigining this should be taken into account.

- Tensairity beam with silicon fabric shows higher natural frequencies than other three.And the rubber fabric having very low natural frequiencies. While desigining this should be taken into account.

- From modal analysis found out that the dimensions of tension and compression element has greater influence in designing.

- The spindle shape Tensairity beam with low modulus of elasticty rod shows greater displacement.Tensairity beam with high modulus of elasticity rod shows minimum displacement.

- $\quad$ Tensairity beam with low modulus of elasticity fabric shows greater displacement.Tensairity beam with high modulus of elasticity shows minimum displacement

- The Tensairity beam with low internal pressure shows greater displacement and beam with high internal 
pressure shows minimum displacement.so spindle shape Tensairity beam with lower internal pressure will produce greater stiffness.

- Tensairity beam with $30 X 10 \mathrm{~mm}$ shows greater displacement than other two dimensions. Tensairity beam with $20 \mathrm{X} 20 \mathrm{~mm}$ shows minimum displacement. so while designing spindle shape Tensairity beam the cross section of tension and compression elements should be consider into account.

\section{REFERENCES}

[1] Theofanis S. Plagianakos, Uwe Teutsch, René Crettol , Rolf H. Luchsinger . "Static response of a spindleshaped tensairity column to axial compression" ;2009.

[2] Cédric Galliot , Rolf H. Luchsinger . "Structural behavior of symmetric spindle-shaped Tensairity girders with reinforced chord coupling";2013.

[3] C. Galliot , R.H. Luchsinger . "A simple model describing the non-linear biaxial tensile behaviour of $P V C$-coated polyester fabrics for use in finite element analysis";2009.

[4] S.L. Veldman, O.K. Bergsma, A. Beukers. "Bending of anisotropic inflated cylindrical beams";2004. 